\title{
FERRAMENTAS DE TECNOLOGIA DA INFORMAÇÃO E COMUNICAÇÃO COMO SUPORTE ÀS ATIVIDADES DO SECRETÁRIO EXECUTIVO
}

\section{INFORMATION AND COMMUNICATION TECHNOLOGY TOOLS IN SUPPORT TO THE EXECUTIVE SECRETARY ACTIVITIES}

Márcia Maria de Medeiros Travassos Saeger Martins Professora pela Universidade Federal da Paraíba - UFPB, Brasil Mestre pela Universidade Federal da Paraíba - UFPB E-mail: marciatsaeger@yahoo.com.br

Danielle Matias da Rocha

Graduada pela Universidade Federal da Paraíba - UFPB, Brasil E-mail: danielematias2010@gmail.com

Tabira de Souza Andrade

Mestre pela Universidade Federal da Paraíba - UFPB, Brasil Professora pela Universidade Federal da Paraíba - UFPB, Brasil E-mail: tabirandrade@yahoo.com.br

Maria Angeluce Soares Perônico Barbotin

Doutora pela Universidade Federal da Paraíba - UFPB, Brasil Professora pela Universidade Federal da Paraíba - UFPB, Brasil E-mail: $\underline{\text { m_peronico@ hotmail.com }}$ 


\title{
FERRAMENTAS DE TECNOLOGIA DA INFORMAÇÃO E COMUNICAÇÃO COMO SUPORTE ÀS ATIVIDADES DO SECRETÁRIO EXECUTIVO
}

\section{RESUMO}

O secretário executivo que almeja se destacar nas organizações deve buscar atender às exigências do mercado, sendo primordial o conhecimento sobre as Tecnologias da Informação e Comunicação. Suas atribuições, adequadas aos modernos padrões de gerenciamento, devem ser exercidas de modo que este profissional possa assessorar os gestores de forma eficiente. Para isto, o secretário executivo deve fazer uso de ferramentas que auxiliem na celeridade de suas ações, tornando-o mais produtivo. Neste contexto, esta pesquisa foi realizada junto a Secretários Executivos e estudantes que já atuam na área ou que se encontram estagiando, objetivando investigar a utilização das ferramentas de Tecnologia da Informação e Comunicação no trabalho do secretário executivo. A coleta de dados se deu por meio de um questionário estruturado, com perguntas objetivas, aplicado no campus IV/UFPB, cujos dados foram analisados de forma quantitativa, com resultados apresentados em tabelas e gráficos. Com base nos resultados, foi possível considerar que a maior parte dos respondentes utiliza ferramentas de TIC em suas atribuições secretariais, estando entre elas o computador e a internet. Verificou-se que a maioria considera que o uso destas ferramentas auxilia na celeridade de suas funções. Dentre os que não fazem uso das ferramentas de TIC, a maior parte alegou que as organizações em que atuam não dispõem destas ferramentas.

Palavras-chave: secretário executivo. Tecnologia da informação e comunicação. Ferramentas de TIC

\section{INFORMATION AND COMMUNICATION TECHNOLOGY TOOLS IN SUPPORT TO THE EXECUTIVE SECRETARY ACTIVITIES}

\begin{abstract}
Executive Secretary who longs to stand in organizations should seek to meet market requirements, with primary knowledge about information and communication technology. Its attributions, proper to modern management standards, must be carried out so that this professional can assist managers efficiently. In order to do so, Executive Secretary should make use of tools that aid in speeding up their actions, becoming more productive. In this context, this research was carried out with the Executive Secretaries and students who already work in the area or who are in trainning programs, aiming to investigate the use of Information and Communication Technology tools in the Executive Secretary work. Data collection was done through a structured questionnaire with objective questions, applied on Campus IV/UFPB, whose data were analyzed quantitatively, with results presented in tables and graphs. Based on the results, it was possible to consider that most respondents use ICT tools in their secretarial assignments, such as the computer and the internet. It was found that the majority believes that the use of these tools helps in managing their time when it comes to their duties. Among those who do not make use of ICT tools, most claimed that the organizations in which they work do not have these tools.
\end{abstract}

Keywords: Executive Secretary. Information and communication technology. ICT tools.

Revista de Gestão e Secretariado - GeSec, São Paulo, v. 6, n. 2, p 65-87, maio./agosto. 2015. 


\section{INTRODUÇÃO}

O secretário executivo desempenha nas organizações várias funções, estando entre elas a de assessor. Para Santos (2010), as funções do secretário executivo são semelhantes às de um administrador, utilizando habilidades de planejamento, organização, coordenação, comando e controle. Para Malagodi (2010), o assessoramento não é um diferencial, mas serve para intermediar a comunicação entre todos os clientes da empresa, evitando ruídos e crises financeiras.

O perfil do secretário executivo vem passando, ao longo do tempo, por várias modificações, de modo a acompanhar as necessidades das organizações (Medeiros e Hernandes, 2010). Assim, o secretário executivo não mais necessita desempenhar apenas as habituais técnicas secretariais, descritas por Santos (2010) como organização de eventos, produção e arquivamento de documentos e etiqueta profissional, mas também deve contribuir no processo de assessoria executiva, necessitando conhecer a estrutura da organização e as estratégias de gestão do negócio.

Para executar suas atividades, o secretário executivo pode fazer uso de ferramentas que lhe permitam agir com maior rapidez. Nas organizações modernas, ainda que de pequeno porte, as Tecnologias da Informação e Comunicação vêm trazendo grandes contribuições na execução das atividades dos profissionais.

Aqueles que possuem domínio das ferramentas de TIC, como computadores e sistemas de informação com base na intranet, além da própria internet, destacam-se no mercado de trabalho e podem utilizar suas potencialidades de maneira a tornar o trabalho mais eficiente. Contudo, nem sempre os profissionais conhecem como as TIC podem contribuir para a execução de suas atividades.

Nesse sentido, D’Elia e Neiva (2009), apontam que o secretário executivo pode utilizar as TIC de forma estratégica para consolidar parcerias, público-alvo, fornecedores, gerenciar suas atividades diárias e gestão sócio-comunicativa com seu público externo e interno. Isso torna estas ferramentas fortes aliadas ao trabalho deste profissional, além de valorizar a autoimagem da empresa. As TICs contribuem também para tornar o secretário executivo um articulador de informações e comunicação em seu ambiente de trabalho, ajudando no crescimento da organização.

Diante da necessidade de utilização das ferramentas de TIC no dia a dia do secretário executivo, este trabalho buscou investigar como as ferramentas da Tecnologia da Informação e Comunicação podem dar suporte ao trabalho do secretário executivo, por meio de uma pesquisa de 
campo, desenvolvida junto a profissionais da área secretarial envolvidos no curso de Secretariado Executivo do campus IV da UFPB, o que configurou objetivo geral da pesquisa.

Dentre os caminhos específicos percorridos para atender a este objetivo geral, se fez necessário evidenciar a evolução que o perfil do secretário executivo sofreu, descrevendo suas atividades desde a criação da profissão até sua inserção no mercado atual; conceituar e identificar as ferramentas de TIC, abordando seu avanço e espaço que ocupa no mercado nos dias atuais; e, identificar quais são as ferramentas de TIC utilizadas no trabalho desse profissional.

Diante das exigências de mercado por profissionais capacitados para atuar em cenários organizacionais com rápida modificação e cada vez mais dependentes da tecnologia, é possível justificar a realização deste estudo por adentrar na temática e investigar qual a utilização das ferramentas da Tecnologia da Informação e Comunicação no trabalho que o secretário executivo desempenha na organização. Porquanto, professores e alunos que atuam na área secretarial responderam ao instrumento de pesquisa, cujos resultados foram analisados segundo abordagem quantitativa, utilizando-se de técnicas estatísticas, com distribuição de frequências e apresentação de tabelas.

\section{A EVOLUÇÃO DO PERFIL DO SECRETÁRIO EXECUTIVO}

A profissão do secretário é umas das mais antigas na história da humanidade, pois desde o antigo Egito, os escribas desempenhavam papéis que requeriam conhecimento cultural, não somente de seu país de origem, mas também de outros povos, o que exigia que este funcionário de alto escalão mantivesse a ética, fidelidade e disponibilidade.

Segundo Sabino e Rocha (2004), os secretários de grandes governantes que lideraram antigamente precisavam estudar, e justamente, tinham de ter a habilidade de ler e escrever, mas não deixavam de dedicar-se a outras atividades.

Apesar de a função secretarial ter sido desempenhada, inicialmente, apenas por homens, as mulheres foram aos poucos se estabelecendo neste mercado. Para Neves (2007, p. 17), "por volta de 1902, havia cerca de 50.000 secretárias mulheres, e isso provocou uma série de alterações nos escritórios. Elas invadiram todo o país e fincaram seus pés em suas posições conquistadas". A referida autora acrescenta que a Primeira Guerra Mundial trouxe à mulher oportunidade de adentrar ainda mais no mercado de trabalho, pois enquanto os homens precisavam estar à frente das guerras, a mulher desempenhava papel secretarial e de estenografia. 
A Segunda Guerra Mundial, ainda segundo argumenta Neves (2007), trouxe mais avanços no campo secretarial, sobretudo nas funções exercidas por mulheres. Após a guerra, o mundo buscou se reerguer dos prejuízos trazidos pelas batalhas e impulsionou o crescimento econômico e profissional. A mulher continuou em ascensão profissional, mas ainda em um patamar inferior em relação aos homens.

O perfil do secretário está em constante modificação, pois os gestores necessitam trabalhar com pessoas que tenham o mesmo pensamento e visão que a empresa precisa para crescer. Esta mudança é exigida devido às alterações no mercado. Hoje, o secretário executivo desempenha novas funções nas organizações e atua de forma mais participativa, colaborando com seu gerenciamento a partir das assessorias que presta (Medeiros e Hernandes, 2010).

O secretário executivo atua como profissional que dá suporte na consecução das tarefas rotineiras. Segundo Medeiros e Hernandes (2010), o secretário deve ter visão estratégica, para assim trabalhar em parceria com os executivos, priorizando de forma tática a empresa onde trabalha. São esses profissionais que dão suporte à tomada de decisão nas organizações.

Para D’Elia e Neiva (2009), lidar com o fluxo de informações das empresas é um desafio que requer do profissional de Secretariado Executivo agilidade. Contudo, para que o secretário executivo possa auxiliar no fluxo de informações, deve ter a habilidade de trabalhar com as informações de forma eficiente, por meio de seu correto processamento.

Em um cenário de mercado onde a tecnologia e suas ferramentas imperam, a era da informação recebe o apoio da Tecnologia da Informação e Comunicação para que o conhecimento seja disseminado em velocidade cada vez maior, superando a barreira do tempo e do espaço.

Para tanto, diante dos recursos tecnológicos disponíveis no mercado, o secretário executivo deve se valer de ferramentas de TIC para trabalhar com informações corretas em menor tempo e tornar-se mais produtivo. Neste sentido, Malagodi (2010) afirma que adaptabilidade, dinamismo, empreendedorismo e sociabilização são algumas das características mais requeridas no mercado de trabalho. Para se destacar no mercado moderno, o secretário executivo necessita conhecer e se adaptar às ferramentas que a TIC oferece. 


\subsection{TECNOLOGIAS DA INFORMAÇÃO E COMUNICAÇÃO E O PROFISSIONAL DE SECRETARIADO EXECUTIVO}

O trabalho desenvolvido nos escritórios vem contando com a contribuição da tecnologia há algumas décadas, desde a utilização de computadores centralizados, através dos mainframes computadores de grande porte, dedicados a armazenar grande volume de informações (Turban, Mclean, Wetherbe \& Leidner, 2004), até os modernos microcomputadores, que em segundos interligam pessoas em diferentes partes do mundo, através da internet e viabilizam a transmissão de informações em tempo real.

É certo que ao longo do tempo a tecnologia evoluiu bastante e as ferramentas utilizadas outrora, na gestão das organizações, devem buscar acompanhar a evolução tecnológica. Sobre este pensamento, Cruz (2002, p. 11) enfatiza:

\footnotetext{
A fase tecnológica mais importante é sempre a última. O que passou, principalmente em se tratando de informática, passou. Em se tratando de fases da informática, elas têm que ser encaradas dessa forma, pois do contrário isso pode vir a custar muito caro para a empresa. O principal custo aqui chama-se manutenção; quer dizer que quanto mais velha a tecnologia, maior seu custo de manutenção.
}

A Tecnologia da Informação pode ser conceituada como "recursos tecnológicos e computacionais para guarda de dados e geração de informação" (Rezende, 2005, p. 32). Para o referido autor, a TI tem em seus fundamentos componentes de hardware - equipamentos e máquinas, software - programas e seus recursos, sistemas de telecomunicações, gestão de dados e informação. Suas aplicações fazem parte do cotidiano das organizações e auxiliam diretamente no controle e na gestão das ações.

A inserção das TIC nas organizações se deu em vários níveis, evoluindo desde contribuições no plano operacional, nos anos de 1950 até a presente contribuição na gestão do conhecimento. Suas fases evolutivas e foco na organização são dispostos na figura 1 .

Revista de Gestão e Secretariado - GeSec, São Paulo, v. 6, n. 2, p 65-87, maio./agosto. 2015. 


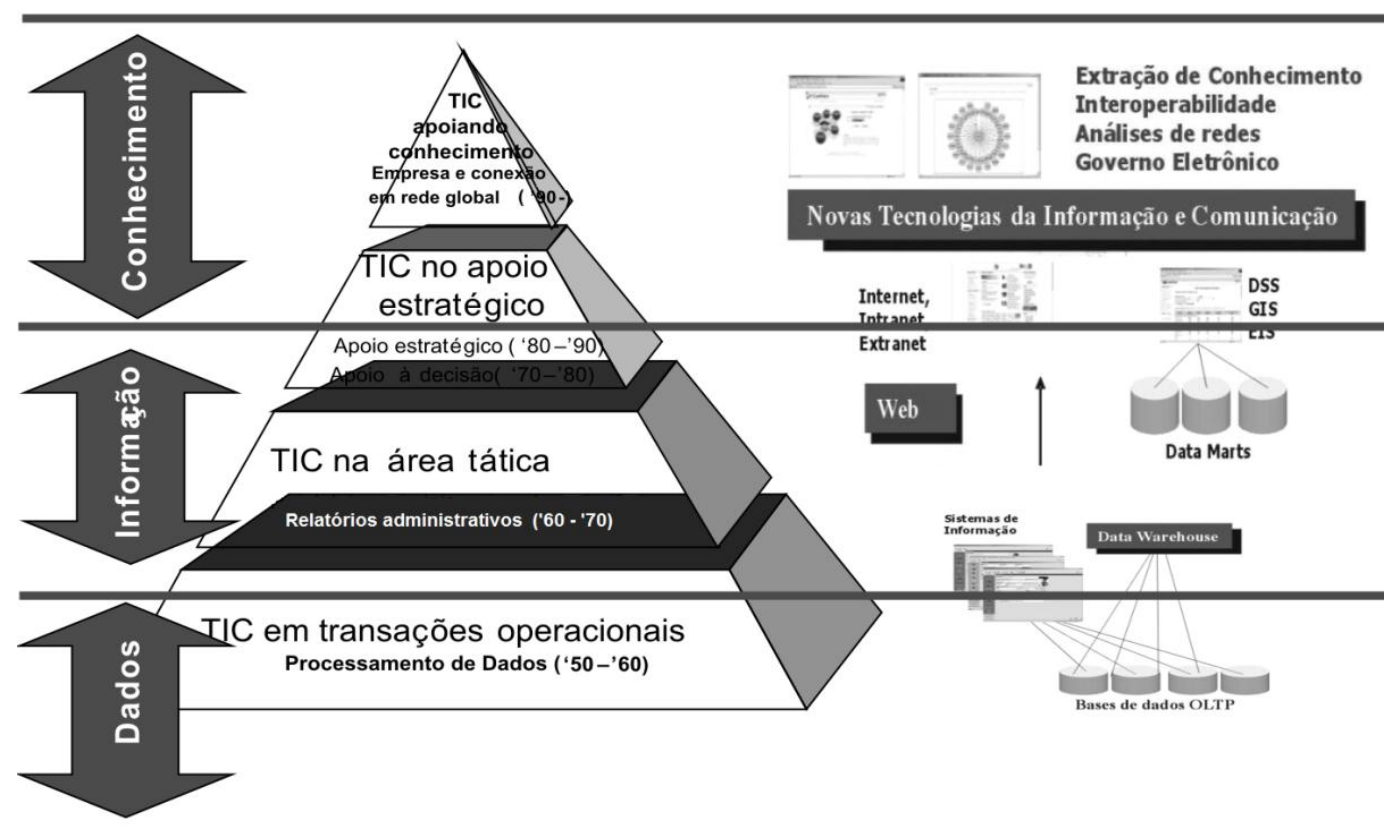

Figura 1. Evolução da Tecnologia da Informação e Comunicação nas organizações

Fonte: Rosseti e Morales (2007, p. 125).

Nesta perspectiva, é possível perceber que os sentidos são direcionados para a gestão de informação por meios computacionais e tecnológicos modernos, para a obtenção de serviços. Mas, para que a TI possa contribuir efetivamente para o sucesso das atividades das organizações, os usuários das ferramentas devem buscar conhecê-las e entender qual o real propósito de sua utilização, evitando assim que as organizações realizem investimentos em tecnologias que acabem sendo desperdiçados pelo uso incorreto. Neste sentido, Saeger (2009, p. 26) enfatiza:

Diante da complexidade dos sistemas que integram estas ferramentas, outro aspecto que pode ser apontado como obstáculo é a dificuldade que os usuários dos sistemas encontram em manuseá-los, posto que geralmente estes são implantados sem a participação daqueles que irão trabalhar direta e indiretamente com estes sistemas.

Desse modo, não basta que as organizações realizem investimentos em modernas ferramentas de tecnologia, visando acompanhar as evoluções de mercado. É necessário inserir tais ferramentas em seu cotidiano capacitando as pessoas que irão fazer uso delas, a fim de que os resultados apontem para aquilo que é esperado.

Tomando por base o entendimento de Da Ponte (2000), antigamente apenas os computadores eram considerados ferramentas de TIC, evoluindo em seguida para impressoras, scanners, mas, hoje diversos dispositivos fazem parte do dia a dia das pessoas, possibilitando sua 
rápida comunicação em qualquer parte do mundo e o uso das TIC não mais se restringe às organizações.

Estas tecnologias não se limitam à vida das empresas. Elas invadiram o nosso cotidiano.

Obtemos dinheiro nas caixas bancárias automáticas, pagamos as nossas despesas em qualquer parte do mundo com dinheiro através dos cartões, usamos telefones celulares, compramos os nossos bilhetes de avião através do nosso computador (Da Ponte, 2000, p. $65)$.

Sendo o secretário executivo responsável pela gestão documental nas organizações e atuando como agente facilitador no fluxo de comunicação, o resultado de seu trabalho fornece subsídio aos gestores, sobretudo de informações. Para D’Elia e Neiva (2009), os secretários devem saber gerenciar de forma eficiente o fluxo de informações da empresa, contribuindo com qualidade para a boa administração das ações organizacionais. Assim, falhas neste processo de gestão das informações podem acarretar falhas na tomada de decisão, o que torna a atividade secretarial diretamente ligada à gestão das organizações.

A manipulação das informações por meio das ferramentas de Tecnologia de Informação e Comunicação torna-se fundamental para que o secretário executivo auxilie de forma eficiente o processo de gerenciamento da informação.

\subsubsection{FERRAMENTAS DA TIC PARA A PROFISSÃO SECRETARIAL}

Conforme já mencionado, a atividade secretarial passou por várias atualizações, buscando acompanhar as tendências de mercado e inovações tecnológicas. Grion (2008, p. 29) reforça esta necessidade afirmando:

Para manter o emprego, a secretária [ou o profissional de Secretariado Executivo] necessita atualizar seu conhecimento. Se ela acomodou-se com o que aprendeu no cargo, fatalmente poderá perder o lugar para máquinas modernas ou para pessoas mais bem preparadas no competitivo mercado de trabalho.

Sendo uma profissão que lida diretamente com a gestão documental, e, por conseguinte, com a transmissão de informações, principalmente no que diz respeito à função de assessoria na gestão organizacional, a atividade secretarial buscou, ao longo de sua evolução, fazer uso das ferramentas que a tecnologia disponibilizava em cada época. Exemplos dessas ferramentas constam no quadro 1, que ilustra a evolução tecnológica para o Secretariado Executivo.

Revista de Gestão e Secretariado - GeSec, São Paulo, v. 6, n. 2, p 65-87, maio./agosto. 2015. 
Quadro 1. Evolução da tecnologia em Secretariado.

\begin{tabular}{|l|l|}
\hline \multicolumn{1}{|l|}{ EVOLUÇÃO DA TECNOLOGIA EM SECRETARIADO } \\
\hline 1870 & Telefone - Máquina de escrever - Papel carbono \\
1880 & Mimeógrafo - Caixa registradora - Máquina de somar \\
1900 & Máquina de estenografia \\
1930 & Mita de duas cores para máquina de escrever \\
1950 & Transistores - Xerox \\
1960 & Computadores com microchip \\
1970 & Microcomputadores - Transmissão de Fac-símile - Calculadoras eletrônicas \\
1980 & Sistemas integrados - software para computadores \\
1990 & Pcs - E-mail - Internet \\
2000 & Aperfeiçoamento da tecnologia de reconhecimento de voz - Assistentes virtuais \\
\hline
\end{tabular}

Fonte: Estado de São Paulo (1999, apud Adelino e Silva, 2012, pp. 15-16).

Nos dias atuais, o profissional de Secretariado Executivo pode contar com ferramentas de TIC como computadores modernos, notebooks, netbooks, tablets, telefone, aparelhos de telefonia móvel, como smartphones, internet, intranet, além dos sistemas de informação utilizados nas organizações.

Essas ferramentas possibilitam o tratamento e a transmissão de informações, em tempo real, além do armazenamento, para que o acesso a elas aconteça sem dificuldades. A rapidez na produção e no acesso às informações e documentos faz com que o secretário executivo possa auxiliar de forma significativa aos gestores na tomada de decisão.

Contudo, conforme já argumentado, o simples uso das TICs não garante ao profissional eficiência em suas atividades, devendo este ter o conhecimento de quais os instrumentos que podem auxiliá-lo em seu cotidiano. Neste aspecto, Adelino e Silva (2012, p. 6) alertam:

O uso desses fantásticos recursos requer uma certa cautela. Para tanto, é preciso atenção ao utilizar essas ferramentas, seus sistemas ou outros meios que façam das informações um diferencial competitivo. O uso adequado das informações, suas possíveis filtragens e dos materiais disponibilizados através dessas redes é que pode, de fato, gerar e utilizar a informação como diferencial competitivo.

Revista de Gestão e Secretariado - GeSec, São Paulo, v. 6, n. 2, p 65-87, maio./agosto. 2015. 
Para que o secretário executivo possa fazer uso eficiente das ferramentas de TIC disponibilizadas pela empresa, é necessário que ele conheça suas potencialidades e tenha interesse pessoal em se aprimorar no uso destas ferramentas. Sob a ótica do interesse pessoal em conhecer ou aperfeiçoar o conhecimento sobre as TICs, Nazareno et al. (2006, p. 34) alertam para o quadro de "apartheid digital entre as regiões geográficas brasileiras", enfatizando a desigualdade no que diz respeito ao acesso à internet e outras tecnologias.

Isso permite considerar que, por vezes, o uso incorreto ou pouco eficiente de algumas ferramentas de TIC nas empresas pode acontecer em virtude da falta de oportunidades ou da capacitação inadequada que o profissional teve até aquele momento, razão pela qual as organizações devem dar o suporte necessário aos seus colaboradores antes de exigir o uso das ferramentas em seu dia a dia.

Este pensamento reforça a ideia de que para que o secretário executivo possa desempenhar bem suas funções, atendendo ao atual perfil demandado pelo mercado, deverá ser um profissional proativo, atencioso e interessado em manter-se atualizado quanto às inovações tecnológicas e estratégicas das organizações.

\section{METODOLOGIA}

A natureza deste trabalho é dedutiva, abrangendo uma pesquisa descritiva, que, para Rampazzo (2005, p. 53), “estuda fatos e fenômenos do mundo físico e, especialmente do mundo humano, sem a interferência do pesquisador" e de natureza quantitativa.

Esta pesquisa também pode ser classificada como uma pesquisa de campo, no que diz respeito à sua aplicabilidade, uma vez que os dados foram coletados no campo de pesquisa. Há de se ressaltar que a literatura pesquisada contemplou, além da temática sobre Secretariado Executivo, temas de áreas afins, como Administração e Sistemas de Informação.

Como o objetivo da pesquisa foi investigar como as ferramentas da Tecnologia da Informação e Comunicação podem dar suporte ao trabalho do secretário executivo, e seu campo de investigação foi o campus IV da UFPB, constitui universo desta pesquisa todos os profissionais que atuam na área secretarial, sejam eles técnicos, docentes ou alunos que já estejam inseridos no mercado de trabalho, incluídos também os que estão estagiando na área.

O levantamento do número de profissionais, feito na etapa da coleta de dados, revelou que a população que poderia ser considerada apta a participar da pesquisa é pequena, razão pela qual não foi necessária a extração de amostra. Nesse sentido, a população da pesquisa foi composta por 58 
pessoas, dentre alunos que estagiam ou que já trabalham na área secretarial e docentes da área. É válido ressaltar que foram contemplados apenas os docentes com formação em Secretariado Executivo.

Para a coleta de dados, foi aplicado, junto aos componentes da população de pesquisa, um questionário estruturado com perguntas objetivas, dividido em duas partes: a primeira, composta por cinco perguntas destinadas a elaborar o perfil dos respondentes, sendo considerados gênero, faixa etária, titulação acadêmica, tempo de atuação na área secretarial e segmento em que trabalha atualmente. $\mathrm{Na}$ segunda parte, foram elaboradas questões que objetivam investigar a utilização da Tecnologia da Informação no trabalho do secretário executivo. Algumas das questões desta etapa permitiram que o respondente acrescentasse mais informações, caso as alternativas não representassem sua única resposta.

A análise dos dados coletados foi feita segundo o método quantitativo, por técnicas estatísticas, com distribuição de frequências e apresentação de tabelas. Para Reis (2008, p. 58), “a pesquisa quantitativa caracteriza-se pelo uso da quantificação na coleta e no tratamento das informações por meio de técnicas estatísticas". Os dados coletados, neste tipo de pesquisa, produzem considerações baseadas em números, havendo pouca ou nenhuma interpretação do pesquisador quanto aos resultados encontrados.

\section{APRESENTAÇÃO E DISCUSSÃO DOS RESULTADOS}

Conforme já informado na descrição da população da pesquisa, 58 pessoas estavam aptas a responder o questionário, dentre alunos que atuam na área secretarial, incluindo estagiários e docentes. Contudo, duas professoras da área não responderam ao questionário, razão pela qual o grupo pesquisado passou a ser de 56 pessoas. A tabela 1 traz a divisão dos componentes do grupo pesquisado por período letivo do curso e atuação.

Tabela 1. Distribuição dos componentes da população.

\begin{tabular}{llll}
\hline Turmas & Trabalha na área & Estagiário & Total \\
\hline P1 & - & - & - \\
\hline P2 & 02 & - & 02 \\
\hline P3 & 01 & - & 01 \\
\hline
\end{tabular}

Revista de Gestão e Secretariado - GeSec, São Paulo, v. 6, n. 2, p 65-87, maio./agosto. 2015. 


\begin{tabular}{llll}
\hline $\mathbf{P 4}$ & - & - & - \\
\hline P5 & 02 & - & 02 \\
\hline P6 & 04 & - & 04 \\
\hline P7 & - & 25 & 25 \\
\hline P8 & 02 & 05 & 07 \\
\hline P9 & 01 & 07 & 08 \\
\hline Concluindo & 04 & - & 04 \\
& & - & 03 \\
\hline Docentes & 03 & $\mathbf{3 7}$ & $\mathbf{5 6}$ \\
\hline Total & $\mathbf{1 9}$ & & \\
\hline
\end{tabular}

Fonte: Dados da pesquisa (2014).

Observa-se, a partir dos dados apresentados, que 66\% do grupo pesquisa é composto por alunos do curso que estão estagiando e 34\% já trabalham na área, sendo 28,5\% (16) alunos do curso e 5,5\% (3) docentes. Dos 56 respondentes, cinco são do sexo masculino e 50 do sexo feminino, representando maioria de mulheres. Um respondente não assinalou a questão que definia gênero.

Quanto à faixa etária, verificou-se que a maior frequência etária entre os respondentes vai até os 30 anos, conforme exposto na tabela 2.

Tabela 2. Distribuição de faixa etária da população.

\begin{tabular}{lll}
\hline FAIXA ETÁRIA & $\begin{array}{l}\text { FREQUÊNCIA } \\
\text { ABSOLUTA }\end{array}$ & $\begin{array}{l}\text { FREQUÊNCIA } \\
\text { RELATIVA }\end{array}$ \\
\hline Até 25 anos & 25 & $44,64 \%$ \\
\hline $\mathbf{2 6}$ a 30 anos & 20 & $35,71 \%$ \\
\hline $\mathbf{3 1}$ a 35 anos & 06 & $10,71 \%$ \\
\hline $\mathbf{3 6}$ a 40 anos & 02 & $3,58 \%$ \\
\hline $\mathbf{4 1}$ a 45 anos & 01 & $1,78 \%$ \\
\hline
\end{tabular}

Revista de Gestão e Secretariado - GeSec, São Paulo, v. 6, n. 2, p 65-87, maio./agosto. 2015. 


\begin{tabular}{lll}
\hline $\mathbf{4 6}$ a 50 anos & 02 & $3,58 \%$ \\
\hline Mais de 50 anos & - & - \\
\hline Total & $\mathbf{5 6}$ & $\mathbf{1 0 0 , 0 \%}$ \\
\hline
\end{tabular}

Fonte: Dados da pesquisa (2014).

No que diz respeito à área de formação, apenas quatro respondentes possuem cursos de pósgraduação, sendo especialização ou mestrado. Nenhum respondente possui apenas a graduação ou cursos de doutorado e pós-doutorado completos, conforme pode ser verificado na tabela 3. A maior parte dos representantes é composta por alunos do campus IV da UFPB.

Tabela 3. Distribuição da área de formação da população.

\begin{tabular}{lll}
\hline GRADUAÇÃO & FREQUENCIA & FREQUENCIA \\
& ABSOLUTA & RELATIVA \\
\hline Graduação incompleta & 52 & $92,86 \%$ \\
\hline Graduação completa & - & $1,78 \%$ \\
\hline Especialização & 01 & $3,58 \%$ \\
\hline Mestrado & 02 & $1,78 \%$ \\
\hline Cursando doutorado & 01 & - \\
\hline Doutorado & - & - \\
\hline Pós-doutorado & - & $\mathbf{1 0 0 \%}$ \\
\hline Total & $\mathbf{5 6}$ & \\
\hline Fonte: Dados da pesquisa $(2014)$ & & \\
\hline
\end{tabular}

Fonte: Dados da pesquisa (2014).

Sobre o tempo de atuação na área secretarial, a maior parte dos respondentes atua há menos de um ano, como pode ser verificado na tabela 4. Dos 56 respondentes, 37 (66\%) são estagiários e atuam há pouco tempo na área secretarial. A menor fatia dos respondentes (quatro) atua na área há mais de seis anos, incluindo-se aqui os docentes que responderam à pesquisa.

Revista de Gestão e Secretariado - GeSec, São Paulo, v. 6, n. 2, p 65-87, maio./agosto. 2015. 
Tabela 4. Distribuição da população por tempo de atuação na área.

\begin{tabular}{lll}
\hline TEMPO DE ATUAÇÃO NA & $\begin{array}{l}\text { FREQUÊNCIA } \\
\text { ABSOLUTA }\end{array}$ & $\begin{array}{l}\text { FREQUÊNCIA } \\
\text { RELATIVA }\end{array}$ \\
AREA (ANOS) & 35 & $62,5 \%$ \\
\hline Menos de 1 & 04 & $7,15 \%$ \\
\hline Mais de 6 & 09 & $16,07 \%$ \\
\hline Entre 4 e 6 & 08 & $14,28 \%$ \\
\hline Entre 1 e 3 & & $\mathbf{1 0 0 \%}$ \\
\hline Total & $\mathbf{5 6}$ & \\
\hline
\end{tabular}

Fonte: Dados da pesquisa (2014).

Finalizando a descrição dos dados que buscaram traçar o perfil dos respondentes, a tabela 5 traz o segmento de mercado em que eles atuam. Os dados revelaram que a maior parte dos respondentes exerce suas funções atualmente no segmento público.

Tabela 5. Distribuição da população por segmento de atuação.

\begin{tabular}{lll}
\hline SEGMENTO QUE ATUA & FREQUÊNCIA & FREQUÊNCIA \\
& ABSOLUTA & RELATIVA \\
\hline Público & 42 & $75,0 \%$ \\
\hline Privado & 14 & $25,0 \%$ \\
\hline Total & $\mathbf{5 6}$ & $\mathbf{1 0 0 \%}$ \\
\hline
\end{tabular}

Fonte: Dados da pesquisa (2014).

Com base nos dados apresentados nas tabelas anteriores, foi possível considerar que o perfil do respondente a esta pesquisa é composto, em sua maioria por mulheres, com faixa etária de até 30 anos, cursando a graduação e com menos de um ano de experiência na área secretarial, sendo o campo de atuação predominante a esfera pública.

Revista de Gestão e Secretariado - GeSec, São Paulo, v. 6, n. 2, p 65-87, maio./agosto. 2015. 


\subsection{INSERÇÃO DE FERRAMENTAS DE TECNOLOGIAS DE INFORMAÇÃO E COMUNICAÇÃO (TIC) NO TRABALHO DO SECRETÁRIO EXECUTIVO}

Para conhecer a utilização de ferramentas de Tecnologia da Informação e Comunicação no trabalho do secretário executivo foi necessário verificar se os respondentes tinham conhecimento acerca das ferramentas. A maior parte deles afirmou saber o que são ferramentas de TIC, conforme exposto na tabela 6. Contudo, o número de respondentes que assinalou não saber o que são ferramentas de TIC foi considerável, em face da relevância que esta temática tem para o secretário executivo.

Tabela 6. Distribuição da população sobre conhecimento sobre as ferramentas de TIC.

\begin{tabular}{llll}
\hline SABE O QUE SÃO FERRAMENTAS DE & FREQUÊNCIA & FREQUÊNCIA \\
TECNOLOGIA DA INFORMAÇÃO & E & $\begin{array}{l}\text { FELATIVA } \\
\text { ABSOLUTA }\end{array}$ & \\
COMUNICAÇÃO? & 35 & $62,5 \%$ \\
\hline Sim & 21 & $37,5 \%$ \\
\hline Não & & $\mathbf{1 0 0 \%}$ \\
\hline Total & $\mathbf{5 6}$ & \\
\hline
\end{tabular}

Fonte: Dados da pesquisa (2014).

Sobre a utilização destas ferramentas nas atribuições cotidianas, dois respondentes não assinalaram a questão. Verificou-se também que a maior parte dos respondentes afirmou utilizar ferramentas de TIC em suas atividades, como pode ser verificado na tabela 7.

Tabela 7. Distribuição da população sobre utilização das ferramentas de TIC no cotidiano.

\begin{tabular}{lll}
\hline $\begin{array}{l}\text { UTILIZA AS FERRAMENTAS DE TIC NO } \\
\text { COTIDIANO? }\end{array}$ & $\begin{array}{l}\text { FREQUÊNCIA } \\
\text { ABSOLUTA }\end{array}$ & $\begin{array}{l}\text { FREQUÊNCIA } \\
\text { RELATIVA }\end{array}$ \\
\hline Sim & 34 & $60,71 \%$ \\
\hline Não & 20 & $35,71 \%$ \\
\hline
\end{tabular}

Revista de Gestão e Secretariado - GeSec, São Paulo, v. 6, n. 2, p 65-87, maio./agosto. 2015. 


\begin{tabular}{lcc}
\hline Não assinalou & 02 & $3,58 \%$ \\
\hline Total & $\mathbf{5 6}$ & $\mathbf{1 0 0 \%}$ \\
\hline
\end{tabular}

Fonte: Dados da pesquisa (2014).

Comparando as respostas desta questão com o que foi assinalado na questão anterior, verificou-se que apenas um respondente que afirmou conhecer o que são ferramentas de TIC não faz uso delas em seu cotidiano.

Essas questões marcaram a primeira etapa da segunda parte do questionário, uma vez que os respondentes que assinalassem que não faziam uso das TIC em seu cotidiano deveriam continuar a responder a partir da $12^{a}$ questão. Contudo, verificou-se que alguns respondentes que afirmaram não conhecer e/ou não fazer uso das TICs em suas atividades cotidianas assinalaram alguns itens das questões 8,9 e 10 . Isso permite considerar que os respondentes poderiam não conhecer o conceito e/ou significado de ferramentas de TIC, mas ao ver sua descrição, afirmou utilizar, razão pela qual tiveram seus dados computados nos resultados.

Tomando como base os 34 respondentes que afirmaram fazer uso das TICs em suas atividades cotidianas, e considerando que as questões 8,9 e 10 ofereciam a opção de cada respondente assinalar mais de um item, foi esperado que cada item fosse assinalado no máximo 34 vezes.

A $8^{\text {a }}$ questão buscou investigar qual (is) a(s) ferramenta(s) de TIC utilizada(s) nas atribuições secretariais cotidianas dos respondentes. Todos os itens foram assinalados ao menos uma vez e três respondentes assinalaram a opção "outros", mas não identificaram nenhuma ferramenta extra. O gráfico 1 ilustra a frequência assinalada para cada item, fazendo um comparativo de todas as opções apresentadas. 
Gráfico 1. Ferramentas de TIC utilizadas nas atribuições cotidianas dos respondentes.

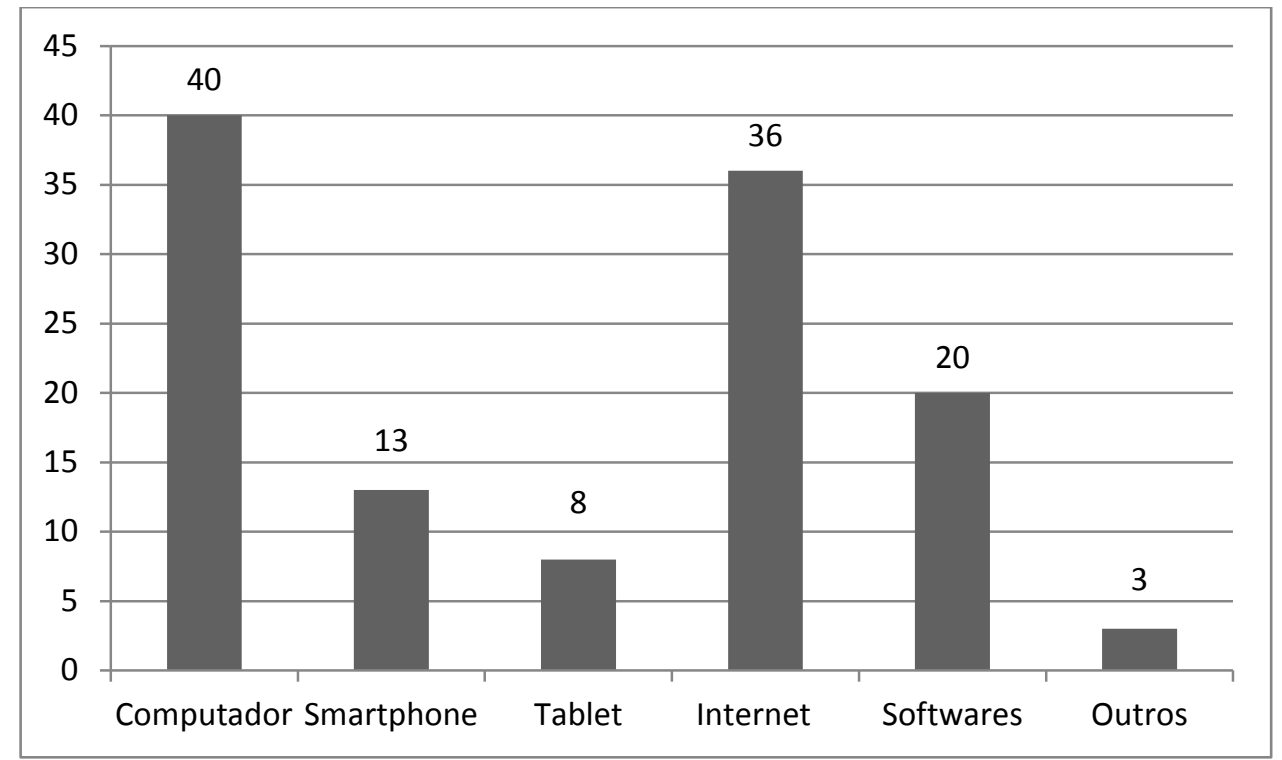

Fonte: Dados da pesquisa (2014).

Dentre as ferramentas mais utilizadas pelos respondentes nas atividades secretariais cotidianas, todos os 34 respondentes que afirmaram fazer uso das TIC em suas atividades assinalaram o computador e a internet. Seis respondentes que assinalaram que não sabiam o que são ferramentas de TIC e/ou não faziam uso delas responderam a questão, apesar da observação de que deveriam passar para a $12^{\mathrm{a}}$ questão. Os seis marcaram que fazem uso do computador e dois, dentre estes seis, marcaram que utilizam a internet em suas atividades secretariais cotidianas, razão pela qual estas duas ferramentas apresentam frequência superior aos 34 respondentes aptos a estas questões.

Como todos os 34 respondentes que fazem uso das ferramentas de TIC em suas atribuições afirmaram trabalhar com o computador habitualmente, este passou a ser também o número máximo esperado para respostas por cada item da $9^{\text {a }}$ questão, que também dava ao respondente a escolha de mais de uma opção. O gráfico 2 traz as ocorrências para cada item dentre os aplicativos mais utilizados no computador. 
Gráfico 2. Aplicativos utilizados no computador.

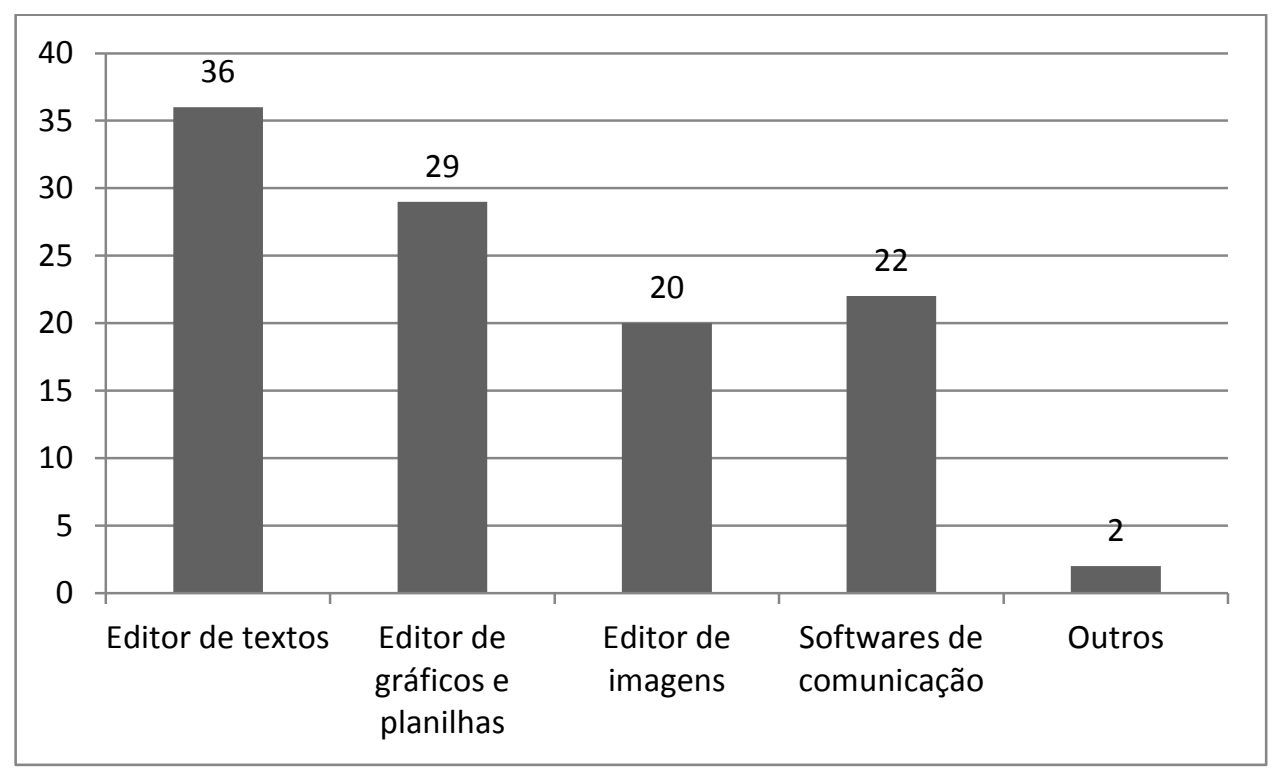

Fonte: Dados da pesquisa (2014).

Foi possível observar nas respostas a esta questão situação semelhante ao ocorrido na questão anterior, pois dois respondentes que afirmaram não fazer uso das ferramentas de TIC assinalaram fazer uso de editores de textos e de gráficos e planilhas, assim como assinalaram fazer uso do computador na questão anterior. Dois respondentes afirmaram utilizar outros aplicativos no computador, mas não descreveram quais são eles. O editor de imagens foi apontado como o aplicativo de computador menos utilizado.

A análise da $10^{\mathrm{a}}$ questão segue a mesma linha das duas questões anteriores, verificando-se também respostas em número superior a 34 em alguns itens. A questão buscou conhecer qual o conteúdo mais acessado por aqueles que assinalaram fazer uso da internet em suas atividades.

Observou-se que todos os respondentes que afirmaram utilizar ferramentas de TIC em suas atividades, incluindo a internet, acessam correio eletrônico e sites de buscas, como pode ser visto no gráfico 3. Os conteúdos menos acessados pelos respondentes são sites de temas específicos da área secretarial, assinalado por quinze pessoas e blogs, assinalados por oito pessoas.

Revista de Gestão e Secretariado - GeSec, São Paulo, v. 6, n. 2, p 65-87, maio./agosto. 2015. 
Gráfico 3. Conteúdo acessado na internet.

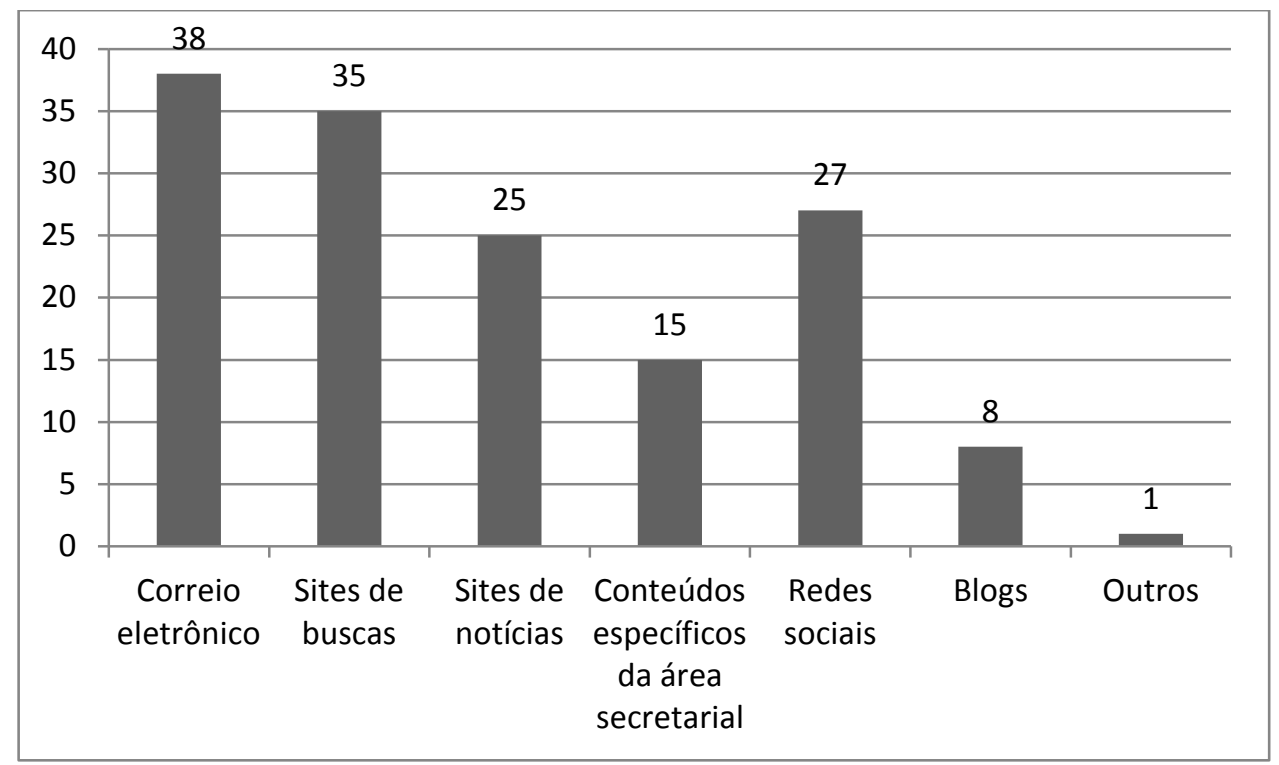

Fonte: Dados da pesquisa (2014).

Foi questionado também se as ferramentas de TIC auxiliam na celeridade das atividades desses profissionais, tendo sido encontradas 42 respostas, sendo duas delas afirmações de que a utilização das ferramentas de TIC não influenciam na realização das atividades cotidianas e 40 respostas afirmando que as ferramentas de TIC contribuem, sim, para a celeridade das ações no trabalho. Nenhum respondente assinalou que as ferramentas de TIC não auxiliam na celeridade das atividades.

É válido ressaltar que todos os 34 respondentes que utilizam ao menos uma ferramenta de TIC em suas atividades afirmaram que elas contribuem para a celeridade na realização do trabalho. Seis respondentes que afirmaram não utilizar ferramentas de TIC assinalaram a opção "sim" para esta questão e dois marcaram a opção "não tem influência".

Por fim, a $12^{\mathrm{a}}$ questão do instrumento de pesquisa era destinada aos respondentes que assinalaram não fazer uso de ferramentas de TIC, na $7^{\mathrm{a}}$ questão, apontando qual(is) o(s) motivo(s) para a não utilização destas ferramentas em suas atividades secretariais. O gráfico 4 apresenta as frequências para cada opção apresentada na questão. 
Gráfico 4. Motivos para a não utilização de ferramentas de TIC nas atividades secretariais.

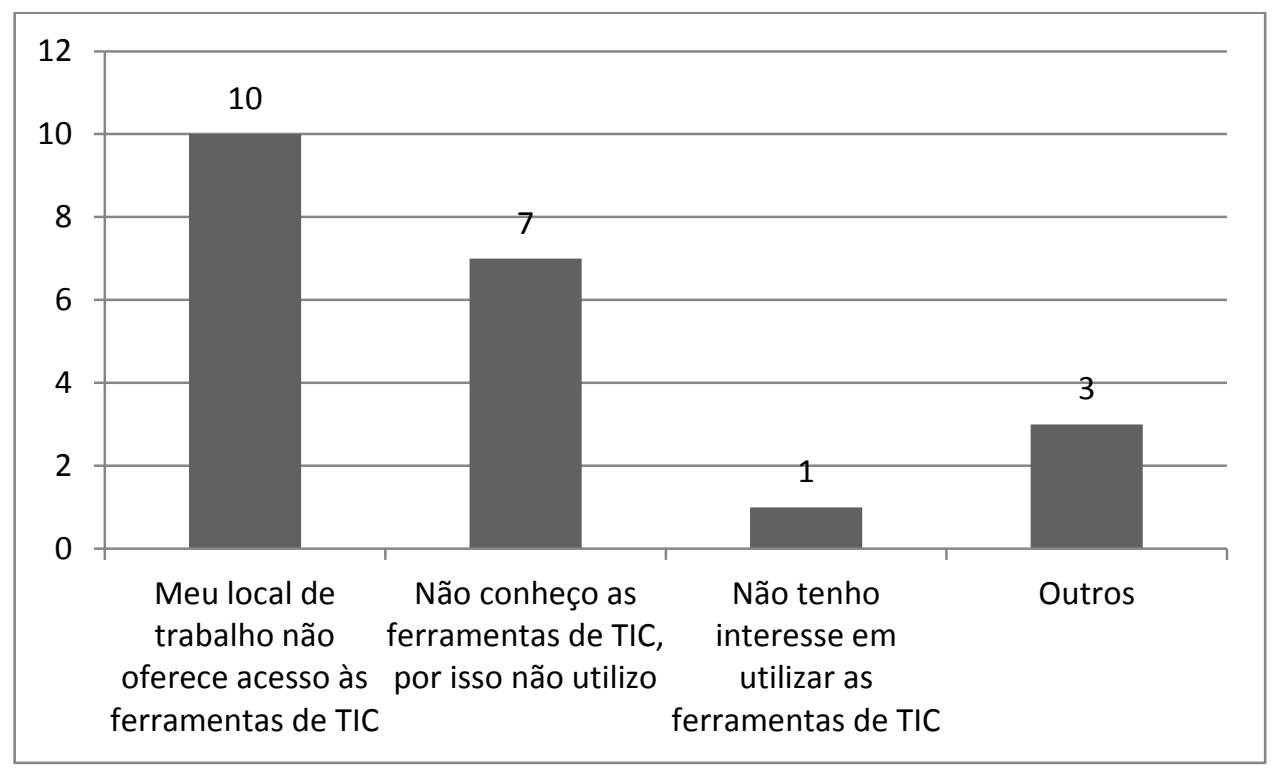

Fonte: Dados da pesquisa (2014).

Dentre os 20 respondentes que assinalaram "não" para a questão 7, que deveriam, conforme instrução do questionário, passar para a $12^{\mathrm{a}}$ questão, três deixaram de marcar esta questão, estando entre os que responderam às questões anteriores e representando número a mais nas respostas encontradas nestas questões.

Assim, ao invés das 20 respostas esperadas nesta questão, foram encontradas 17 e a maior parte dos respondentes assinalou apenas um item. O que obteve maior número de respostas foi o que apontou a falta de acesso às ferramentas de TIC no local de trabalho, com 10 inferências e 7 respondentes afirmaram não utilizar as ferramentas de TIC por não conhecê-las. Um respondente afirmou que não faz uso das ferramentas de TIC por falta de interesse e três respondentes assinalaram, além de um dos motivos citados, a opção "outros", mas não especificaram a razão da não utilização.

Apresentados os dados obtidos com a aplicação do questionário, elaborando um perfil dos respondentes e apresentando a utilização das ferramentas de TIC em suas atribuições secretariais, foram tecidas as considerações finais deste estudo. 


\section{CONSIDERAÇÕES FINAIS}

A área de Secretariado Executivo vem apresentando modificações quanto à sua posição no mercado e, consequentemente, na estruturação dos cursos, uma vez que estes também devem ser modificados, de modo a dar o suporte necessário, no que diz respeito ao conhecimento, para que os profissionais saiam das universidades aptos a atender ao novo perfil secretarial. O secretário executivo ganhou espaço considerável no campo de trabalho no Brasil, com habilidades, ferramentas, participação na gestão do fluxo de comunicação, destreza e postura ética.

Nas últimas décadas, a tecnologia e seu arsenal de ferramentas disponíveis no mercado global conseguiu transformar a prestação de serviço nas organizações, inserindo-se também nas práticas secretariais. A gestão da informação passou a ser fundamental para a sobrevivência das organizações.

Assim, na tentativa de investigar como as ferramentas da Tecnologia da Informação e Comunicação podem dar suporte ao trabalho do secretário executivo, foi desenvolvido este trabalho, como uma pesquisa de campo, realizada no campus IV da UFPB, junto a 56 profissionais atuantes na área secretarial, sendo três docentes e 53 alunos do curso de Secretariado Executivo. Dentre estes alunos, 19 trabalham na área secretarial e 37 estagiam.

O perfil do respondente a esta pesquisa é composto, em sua maioria, por mulheres com faixa etária de até 30 anos, cursando a graduação e com menos de um ano de experiência na área secretarial, sendo o campo de atuação predominante na esfera pública.

A maior parte dos respondentes afirmou utilizar ferramentas de TIC em suas atribuições secretariais, sendo apontados em maior medida os computadores, a internet, e softwares. Os aplicativos mais usados no computador são os editores de textos, planilhas e gráficos e softwares de comunicação. Isso é um parâmetro de que a utilização do computador e suas ferramentas auxilia o secretário executivo na produção de cartas oficiais, dentre elas memorandos, declarações e ofícios, edição de atas, gráficos de mercadorias e alimentos, listas de compra de materiais e pesquisa de preços. Ressalte-se que alguns dos respondentes que afirmaram fazer uso destas ferramentas desconheciam seus significados, quando da realização do estudo.

A pesquisa identificou também que há locais de trabalho que não utilizam ferramentas de TIC, tendo em vista que os respondentes afirmaram que seu local de trabalho não as disponibiliza. Considerando que a profissão de Secretariado está entre as dez profissões que mais se expandem no Brasil, é fundamental o uso de ferramentas que auxiliem na produtividade destes profissionais. 
Destarte, verifica-se que a prática de algumas empresas em não disponibilizar tecnologias que auxiliem na celeridade do trabalho do secretário executivo vai de encontro às modernas concepções organizacionais, fazendo-se mister que tais práticas gerenciais sejam revistas.

A Tecnologia da Informação e Comunicação serve como instrumento facilitador no processo de aprendizagem e na prática das atividades organizacionais e ajuda a manter um elo de comunicação entre fornecedores, clientes internos e externos e a direção da empresa. Neste sentido, este estudo partiu da premissa de que a utilização das ferramentas de TIC oferece relevante suporte às atividades do secretário executivo, contribuindo para a celeridade de suas ações e tornando-o um profissional mais eficiente. Contudo, apesar do uso crescente das tecnologias nas atividades secretariais, a pesquisa revelou a necessidade de atualização de práticas gerenciais em algumas organizações onde o secretário executivo ainda atua sem o suporte das tecnologias, estando em uma realidade não mais existente no mercado atual.

\section{REFERÊNCIAS}

Adelino, Francisca Janete Silva \& Silva, Maria Aparecida Vito (jul.-/dez. 2012). A Tecnologia da Informação como agente de mudança no perfil do profissional de Secretariado. Revista de Gestão e Secretariado, São Paulo, v. 3, n. 2, pp. 5-23.

Cruz, Tadeu (2002). Sistemas, organização e métodos: estudo integrado das novas tecnologias da informação e introdução à gerência do conteúdo e do conhecimento (3a ed.). São Paulo: Atlas.

Da Ponte, João Pedro (2000). Tecnologias de informação e comunicação na formação de professores: que desafios? Revista Iberoamericana de Educación, n. 24, pp. 63-90.

D’Elia, Maria Elziabete Silva \& Neiva, Edméa Garcia, (2009). As novas competências do profissional de secretariado (2a ed.). São Paulo: IOB.

Grion, Laurinda (2008). A nova secretária: metacompetente proativa dinâmica. São Paulo: Madras.

Malagodi, Beatriz (2010). A secretária do século XXI: posturas, atribuições e responsabilidades. Recuperado em 20 agosto, 2013, de <http://www.administradores.com.br〉.

Martins, Rosilda Baron (2006). Metodologia científica. Curitiba: Juruá.

Medeiros, João Bosco \& Hernandes, Sônia (2010). Manual da secretária (12a ed.) São Paulo: Atlas, 2010.

Revista de Gestão e Secretariado - GeSec, São Paulo, v. 6, n. 2, p 65-87, maio./agosto. 2015. 
Nazareno, Cláudio et. al. (2006). Tecnologias da informação e sociedade: o panorama brasileiro. Brasília: Câmara dos Deputados, Coordenação de Publicações.

Neves, Maria da Conceição de Oliveira (2007). Introdução ao Secretariado Executivo. Rio de Janeiro: T. Mais.Oito.

Nonato Júnior, Raimundo (2009). Epistemologia e Teoria do Conhecimento em Secretariado Executivo: a fundação das ciências da assessoria. Fortaleza: Expressão Gráfica.

Rampazzo, Lino (2005). Metodologia científica: para alunos dos cursos de graduação e pósgraduação. (3a ed.) São Paulo: Edições Loyola.

Reis, Linda G. (2008). Produção de monografia: da teoria à prática (2a ed.). Brasília: Senac-DF.

Rezende, Denis Alcides (2005). Engenharia de software e sistemas de informação (3a ed.). Rio de Janeiro: Brasport.

Rosseti, Adroaldo Guimarães \& MORALES, Aran Bey Tcholakian (jan.-abr. 2007). O papel da tecnologia da informação na gestão do conhecimento. Ci. Inf., Brasília, vol. 36, n. 1, pp. 124135 .

Sabino, Rosimere Ferraz \& Rocha, Fábio Gomes (2004). Secretariado: do escriba ao webwrite. Rio de Janeiro: Brásport.

Saeger, Márcia Maria de Medeiros Travassos. A política do Cartão Nacional de Saúde sob a ótica dos usuários do SUS na região metropolitana de João Pessoa e Recife. Dissertação de Mestrado. João Pessoa: [s.n.], 2010.

Santos, Júlio Cesar de Souza (2010). Secretariado: funções, atribuições e perfil profissional. Recuperado em 27 agosto, 2013, de <http://meuartigo.brasilescola.com>.

Turban, Efraim; Mclean, Ephraim; Wetherbe, James \& Leidner, Dorothy (2004). Tecnologia da informação para gestão: transformando os negócios na economia digital (3a ed.). Porto Alegre: Bookman.

Wainer, Jacques (2003). O paradoxo da produtividade In: Ruben, Guilhermo; Wainer, Jacques \& Dwyer, Tom (Org.) Informática, organizações e sociedade no Brasil. São Paulo: Cortez.

Revista de Gestão e Secretariado - GeSec, São Paulo, v. 6, n. 2, p 65-87, maio./agosto. 2015. 